\title{
ЭМПИРИЧЕСКИЙ АНАЛИЗ ВЗАИМОСВЯЗИ КАЧЕСТВА ЖИЗНИ И МИГРАЦИИ НАСЕЛЕНИЯ В СУБЪЕКТАХ РОССИЙСКОЙ ФЕДЕРАЦИИ
}

\author{
() 2019 Фахрутдинова Елена Валерьевна \\ Казанский (Приволжский) федеральный университет, Россия, Казань \\ E-mail: efahr@mail.ru \\ (c) 2019 Юрков Дмитрий Васильевич \\ Казанский (Приволжский) федеральный университет, Россия, Казань
}

Материальный фундамент жизнедеятельности человека составляет производство благ посредством добычи и переработки природных ресурсов. Противоречивость этого процесса с позиции обеспечения высокого уровня жизни и темпов экономического роста, с одной стороны, и качества жизни и качества экономической динамики, с другой стороны, очевидна. Интенсификация воздействия на окружающую природную среду способна обеспечить высокий уровень жизни, но качество жизни во многом обусловлено минимизацией рисков разрушающего воздействия экономической деятельности на окружающую среду. Соблюдение эколого-экономического баланса природопользования и сохранности качественного состояния природного богатства выступает необходимым условием разрешения данного противоречия. Методологическим приоритетом межвременного выбора в теории качества жизни остается принцип справедливого распределения накопленного капитала, в т.ч. человеческого и природного, между поколениями. Одной из форм инвестиций в человеческий капитал, как известно, выступает миграция рабочей силы, обусловленная ожиданиями мигрантов не только роста доходов, но и в целом повышения качества жизни их семей.

В основе многих теоретико-методологических подходов к исследованию миграции населения находится гипотеза, согласно которой улучшение качества жизни выступает основной целью миграции. Актуальная стратегическая задача научного сообщества заключается в разработке теоретико-методологических основ механизма и прикладных рекомендаций по привлечению квалифицированных мигрантов на основе повышения качества жизни населения, включая продвижение институтов развития и методическое обеспечение таргетированных миграционных потоков.

Показателен в этом отношении пример
Стратегии социально-экономического развития Республики Татарстан до 2030 года. Примененный в Республике Татарстан подход в части управления реализацией Стратегии отличает разработка предложений по укреплению системы республиканских институтов развития, ориентированных на повышение качества жизни населения республики. «В Республике Татарстан создана и эффективно работает система стратегического управления развитием Республики Татарстан - комплексная гармоничная система управления, нацеленная на устойчивое развитие, создание условий для повышения конкурентоспособности экономики и качества жизни» [1]. Действующая система управления в республике обеспечивает ее конкурентные преимущества и, в частности, стабильное четвертое место в рейтинге российских регионов по качеству жизни на протяжении периода с 2015 по 2018 годы и положительный миграционный прирост.

Теоретически модель «инвестиции-выгоды» миграции может быть представлена в следующем виде [2]:

$$
P V N B_{i}=\sum_{t=T_{o}}^{T_{R}} \frac{B_{i t}-B_{0 t}}{(1+r)^{t}}-C_{i}>0
$$

где $\mathrm{PVNB}_{i}-$ приведенная стоимость чистой денежной выгоды от миграции в страну $i$;

$\mathrm{T}_{0}$ - год миграции;

$\mathrm{T}_{\mathrm{R}}$ - год окончания получения дохода;

$\mathrm{B}_{\mathrm{it}}$ - доходы в регионе-реципиенте і в году $\mathrm{t}$;

$\mathrm{B}_{0 \mathrm{t}}$ - доходы в регионе-доноре в году $\mathrm{t}$;

$\mathrm{r}$ - индивидуальная ставка дисконтирования;

$\mathrm{C}_{i}-$ прямые издержки миграции.

Если по оценкам неравенство (1) выполняется, то решение о миграции принимается, в противном случае - отвергается.

По сути, при принятии решения о миграции в этой модели используется методология и инструментарий теории инвестиционного анали- 
за. Затраты на переезд и обустройство на новом месте сравниваются с объемом будущих социальных и экономических выгод (ростом уровня доходов и качества жизни) с использованием инструментария дисконтирования. Решение о миграции принимается потенциальным мигрантом в случае положительного значения чистой текущей стоимости.

Несмотря на существование других теоретико-методических подходов к объяснению причин миграции, аналитический аппарат теории качества жизни, рационально объясняющий миграционные потоки ожиданиями роста благосостояния, повышением качества медицинских и образовательных услуг, следует отметить как эффективный метод экономического анализа поведения мигрантов и последствий миграции. Критически отмечаемое некоторыми учеными расхождение в уровнях анализа, проявляющееся в том, что теоретическая модель рассматривает экономическое поведение рационального индивида, а исследования миграции требуют анализа на мезо- и макроуровнях, преодолевается посредством применения аппарата многоуровневого анализа.

Протестируем гипотезу обусловленности мобильности граждан Российской Федерации ожиданиями повышения качества жизни, посредством переезда в регионы с большей заработной платой и лучшими условиями жизни, медицинским обеспечением, условиями обучения и воспитания детей, а также экологией.

В рамках теории качества жизни логично проверить гипотезу наличия значимой стати-
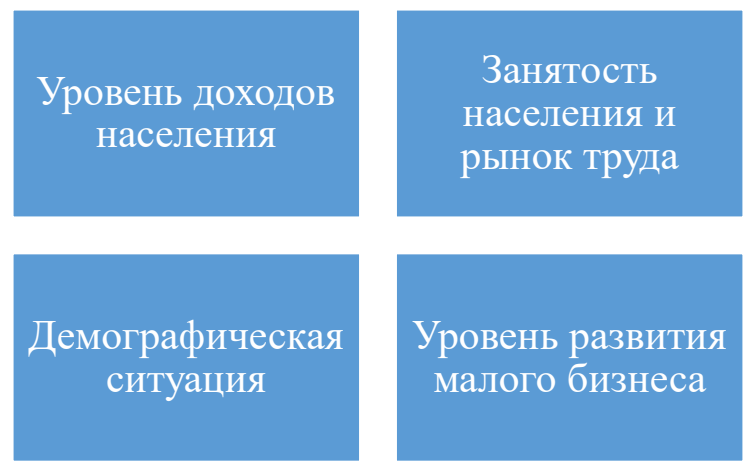

стической связи между параметрами миграционного потока в субъектах Российской Федерации и мерами качества жизни в этих регионах. Для этого проанализируем датасеты рейтинга российских регионов (85 субъектов РФ) по качеству жизни за период 2015-2018 гг. [3], коэффициента миграционного прироста [4] и показателей общих итогов миграции населения по 85 субъектам Российской Федерации за соответствующие годы[5]. Из последней группы данных были использованы: число прибывших и число выбывших.

Предварительно значения интегрального индикатора качества жизни, числа прибывших и числа выбывших по субъектам РФ были преобразованы в соответствующие индексы размерностью в интервале $[-1,1]$ по следующей формуле:

$$
\text { Индекс }=\left(X-X_{\min }\right) /\left(X_{\max }-X_{\min }\right)
$$

где $\mathrm{X}$ - фактическое значение показателя субъекта РФ;

$\mathrm{Xmax}, \mathrm{Xmin}$ - максимальное и минимальное значения данного показателя по всем субъектам РФ.

Рейтинг субъектов РФ по качеству жизни построен по данным Росстата, Минздрава, Минфина, Центробанка и других открытых источников. Рейтинг сформирован из показателей, отражающих разные аспекты условий жизни и состояния национальной экономики. При построении рейтинга были проанализированы 70 показателей, агрегированных в 11 групп (рис. 1).

Результаты проведенного статистического анализа в известной степени подтверждают
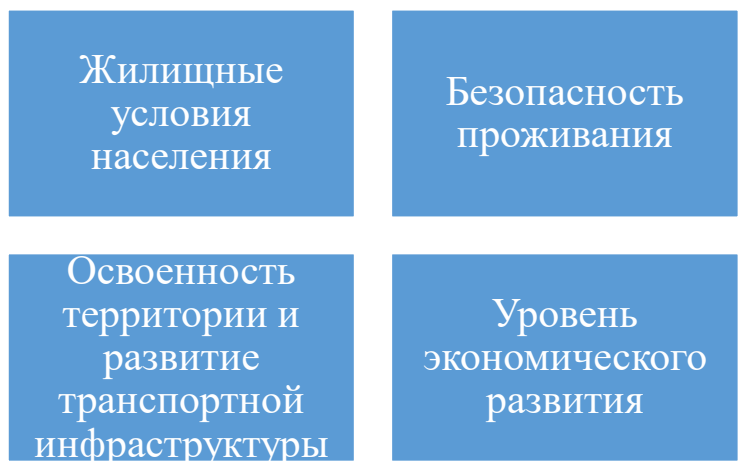
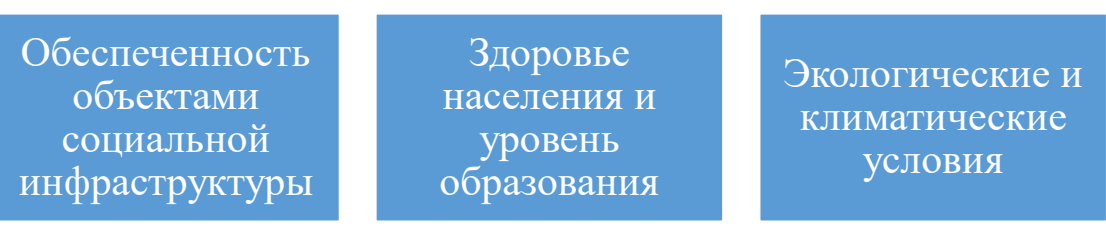
тестируемую гипотезу, позволяя объяснять и отчасти прогнозировать внутрироссийские миграционные потоки между субъектами РФ. На основе мезоэкономических данных обосновано наличие миграционных потоков, направленных в субъекты РФ с более высоким качеством жизни населения (рис. 2). Это означает наличие большого количество мигрантов, принимающих рациональные решения по повышению качества и уровня жизни.

Так, значение коэффициента парной корреляции показателя миграционного прироста и индекса качества жизни составил 0,60271899 . Следовательно, оценка тесноты связи по шкале Чеддока определяется как заметная. Хотя следует признать, что для построения прогнозов этого недостаточно. Прогностическое моделирование обычно производится при значении коэффициента парной корреляции, превышающем 0,7. Коэффициент детерминации также недостаточен. Его значение показывает, что полученное уравнение линейной регрессии лишь на $36,33 \%$ объясняет поведение выбранных признаков.

Для построения модели линейной регрессии был применен программный продукт Gretl. Peзультат моделирования представлен в таблице 1 , где Y - коэффициент миграционного прироста, $\mathrm{X}$ - индекс качества жизни.

Коэффициенты при переменных модели значимы на уровне $\alpha=0,01$, т.е. с надежностью $99 \%$.

Корреляционный и регрессионный анализ

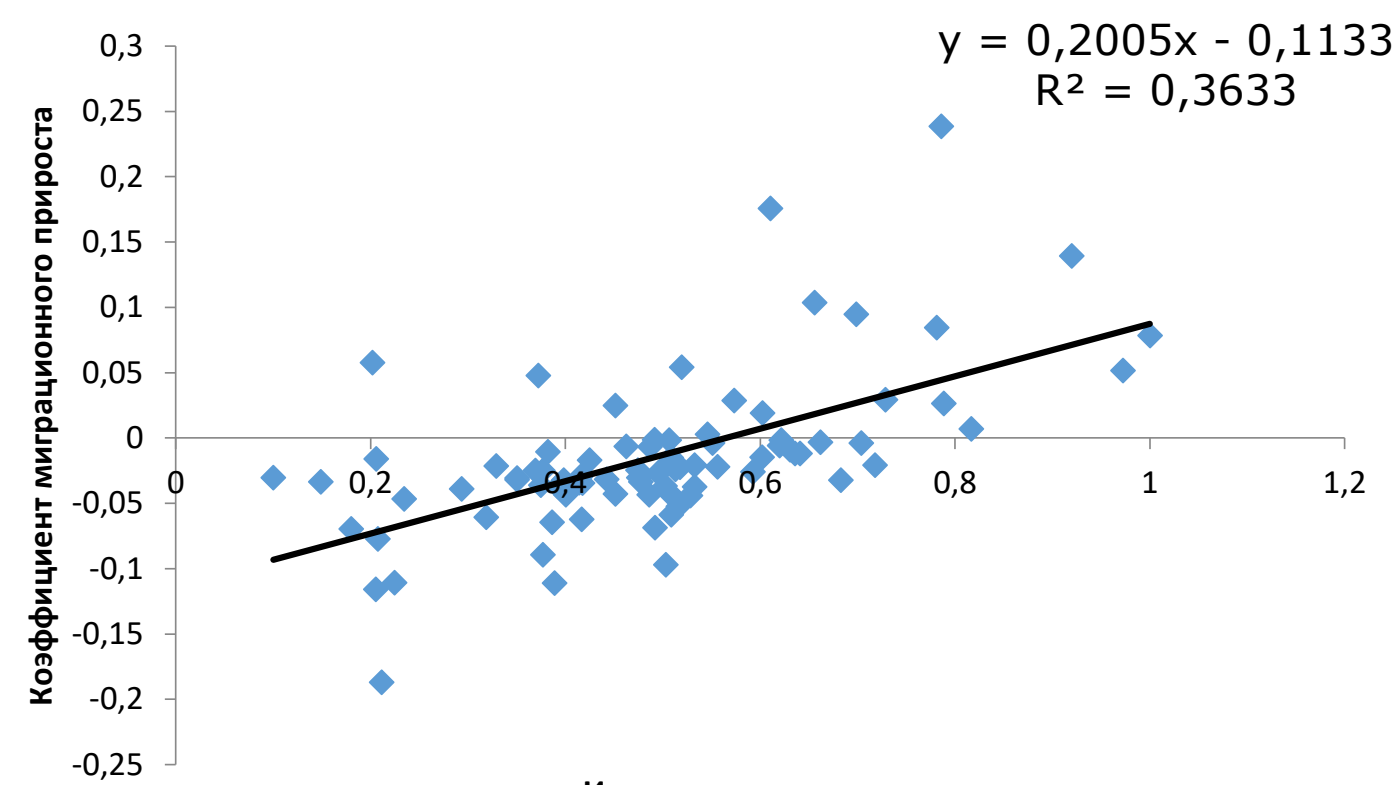

Индекс качества жизни

Puc. 2. Зависимость между коэффициентом миграционного прироста и индексом качества жизни по 85 субъектам РФ по данным за 2015-2018 гг.

Таблица 1. Модель 1: МНК, использованы наблюдения 1-85 Зависимая переменная: Y

\begin{tabular}{|l|c|c|c|c|c|}
\hline & Коэффициент & Ст. ошибка & t-статистика & $P$-значение & \\
\hline const & $-0,113291$ & 0,0152583 & $-7,4248$ & $<0,0001$ & $* * *$ \\
\hline $\mathrm{X}$ & 0,20053 & 0,0291409 & 6,8814 & $<0,0001$ & $* * *$ \\
\hline
\end{tabular}

\begin{tabular}{|l|c|l|l|c|}
\hline Среднее зав. перемен & $-0,014604$ & & Ст. откл. зав. перемен & 0,059841 \\
\hline Сумма кв. остатков & 0,191525 & & Ст. ошибка модели & 0,048037 \\
\hline R-квадрат & 0,363270 & & Испр. R-квадрат & 0,355599 \\
\hline $\mathrm{F}(1,83)$ & 47,35356 & & Р-значение (F) & $1,04 \mathrm{e}-09$ \\
\hline Лог. правдоподобие & 138,4442 & & Крит. Акаике & $-272,8885$ \\
\hline Крит. Шварца & $-268,0032$ & Крит. Хеннана-Куинна & $-270,9235$ \\
\hline
\end{tabular}


следующей пары признаков: индекса качества жизни и индекса числа прибывших по субъектам РФ с большей значимостью подтверждает тестируемый тезис (рис. 3). Об этом свидетельствует большая степень тесноты связи между тестируемыми признаками (коэффициент корреляции $=0,7)$ и более высокое значение коэффициента детерминации. Полученная модель линейной регрессии объясняет 48,5\% выявленной связи (таблица 2), где Y - индекса числа прибывших, $\mathrm{X}$ - индекс качества жизни.

Исходя из полученных результатов, логично провести корреляционный и регрессионный анализ индекса качества жизни и индекса числа выбывших по субъектам РФ. Результаты моделирования свидетельствует практически о той же степени тесноты связи, что и в случае анализа связи индекса качества жизни и индекса числа прибывших (рис. 4). Коэффициент корреляции в этом случае равен 0,67. Параметры модели линейной регрессии представлена в таблице 3 , где Y - индекса числа выбывших, X - индекс качества жизни.

На основании полученных результатов можно сделать вывод, что с ростом качества жизни в субъекте РФ увеличивается как приток, так и отток мигрантов, но с различной динамикой и разной структурой потока. В большинстве субъектов РФ с высоким качеством жизни наблюдается положительный естественный прирост населения (рис. 5) и наоборот. Этот факт также подтверждает гипотезу привлекательности для мигрантов регионов с высоким качеством жизни населения.

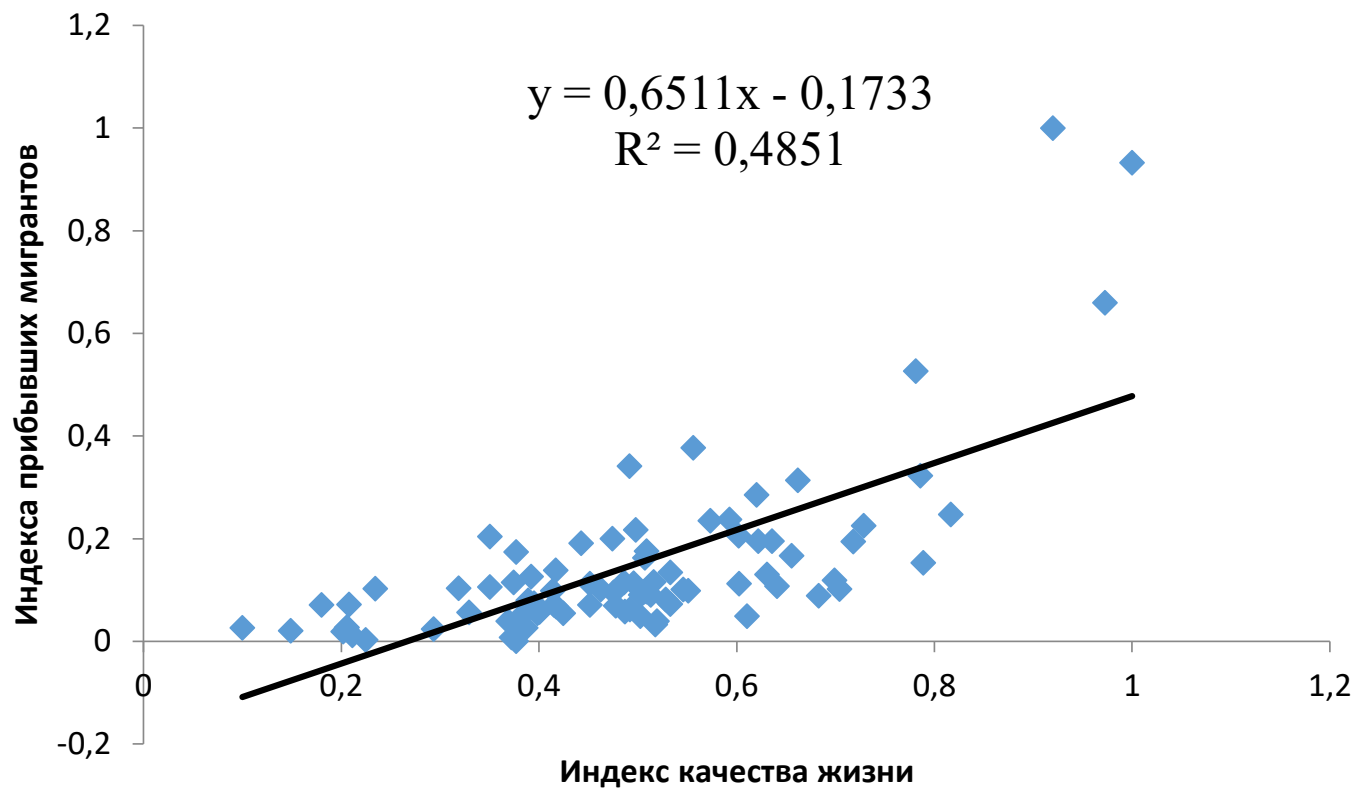

Puc. 3. Зависимость между индексом числа прибывших мигрантов и индексом качества жизни по 85 субъектам РФ по данным за 2015-2018 гг.

Таблица 2. Модель 2: МНК, использованы наблюдения 1-85 Зависимая переменная: Y

\begin{tabular}{|l|c|c|c|c|c|}
\hline & Коэффициент & Ст. очибка & $t$-статистика & $P$-значение & \\
\hline const & $-0,173327$ & 0,0385534 & $-4,4958$ & $<0,0001$ & $* * *$ \\
\hline $\mathrm{X}$ & 0,651061 & 0,0736308 & 8,8422 & $<0,0001$ & $* * *$ \\
\hline
\end{tabular}

\begin{tabular}{|l|c|l|l|c|}
\hline Среднее зав. перемен & 0,147080 & & Ст. откл. зав. перемен & 0,168133 \\
\hline Сумма кв. остатков & 1,222751 & & Ст. ошибка модели & 0,121375 \\
\hline R-квадрат & 0,485064 & & Испр. R-квадрат & 0,478860 \\
\hline $\mathrm{F}(1,83)$ & 78,18495 & & Р-значение (F) & $1,35 \mathrm{e}-13$ \\
\hline Лог. правдоподобие & 59,65600 & & Крит. Акаике & $-115,3120$ \\
\hline Крит. Шварца & $-110,4267$ & Крит. Хеннана-Куинна & $-113,3470$ \\
\hline
\end{tabular}




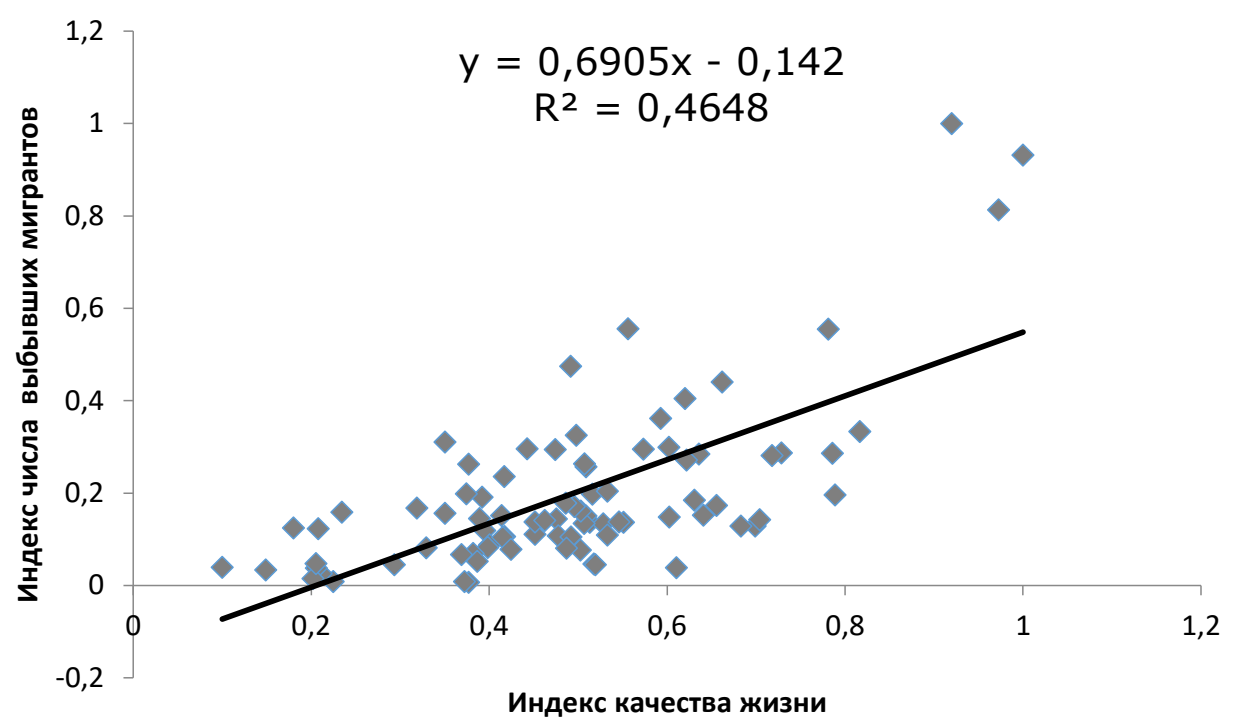

Puc. 4. Зависимость между индексом числа выбывших мигрантов и индексом качества жизни по 85 субъектам РФ по данным за 2015-2018 гг.

Таблица 3. Модель 3: МНК, использованы наблюдения 1-85 Зависимая переменная: Y

\begin{tabular}{|l|c|c|c|c|c|}
\hline & Коэффициент & Ст. ошибка & -статистика & $P$-значение & \\
\hline const & $-0,139507$ & 0,0435582 & $-3,2028$ & 0,0019 & $* * *$ \\
\hline $\mathrm{X}$ & 0,683809 & 0,0830831 & 8,2304 & $<0,0001$ & $* *$ \\
\hline
\end{tabular}

\begin{tabular}{|l|c|l|l|c|}
\hline Среднее зав. перемен & 0,197821 & & Ст. откл. зав. перемен & 0,182145 \\
\hline Сумма кв. остатков & 1,534488 & & Ст. ошибка модели & 0,135970 \\
\hline R-квадрат & 0,449383 & & Испр. R-квадрат & 0,442749 \\
\hline $\mathrm{F}(1,83)$ & 67,73996 & & Р-значение (F) & $2,26 \mathrm{e}-12$ \\
\hline Лог. правдоподобие & 50,00454 & & Крит. Акаике & $-96,00907$ \\
\hline Крит. Шварца & $-91,12377$ & Крит. Хеннана-Куинна & $-94,04407$ \\
\hline
\end{tabular}

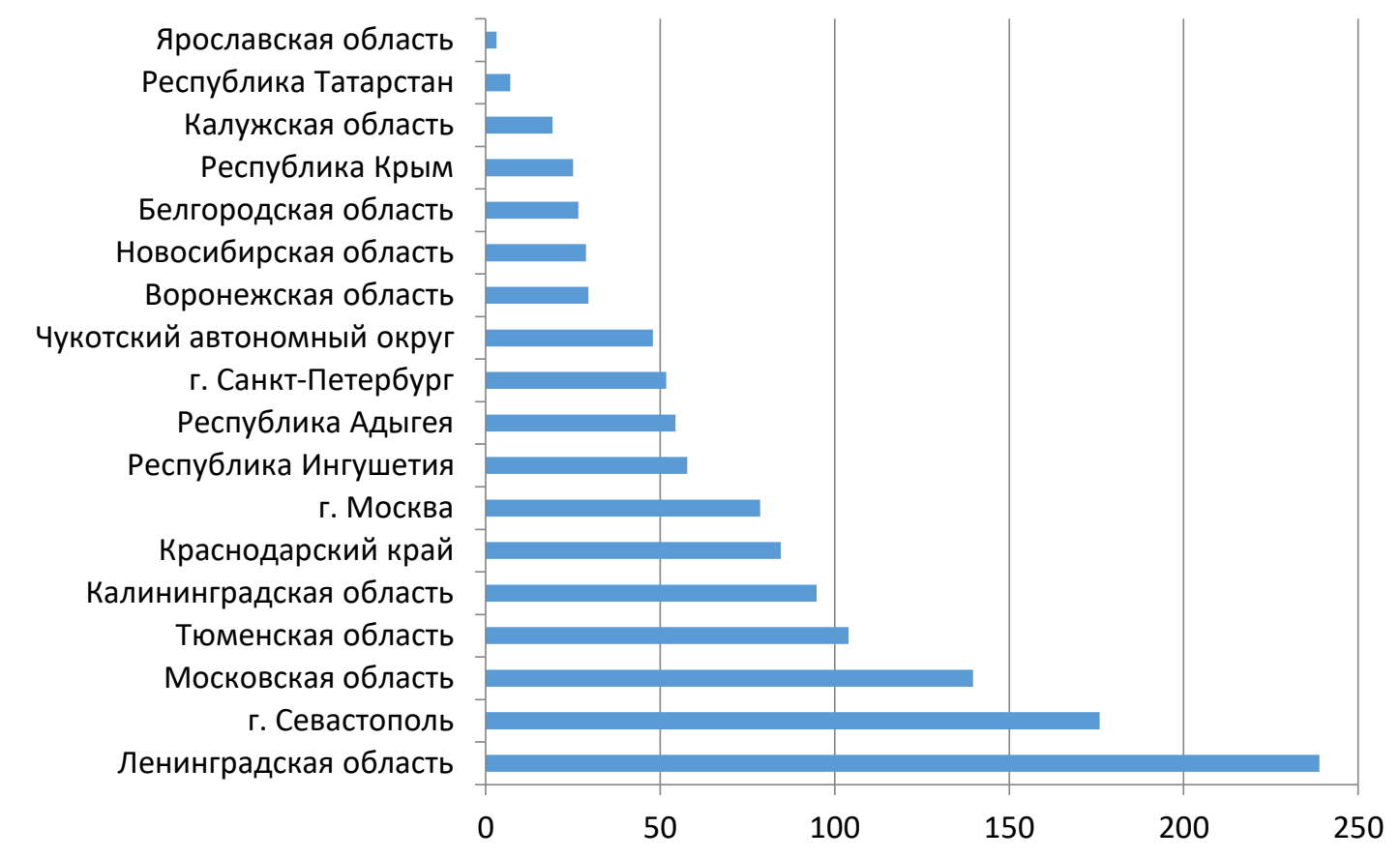

Рис. 5. Коэффициент миграционного прироста, чел. (на 10000 чел.) 
Существенное превышение объемов миграционных потоков в пределах России над миграционными потоками за пределы России усиливает значение теории качества жизни. Поскольку принятие решения о миграции на близкие расстояния более предсказуемо и основано на более достоверной информации при расчете экономической эффективности миграции на основе сопоставления затрат и выгод, что позволяет человеку принимать более обоснованные решения по миграции. Волатильность прогноза эффективности миграции на дальние расстояния более высока. Экономическим эффектам и рискам такой миграции свойственна большая неопределенность. Это, соответственно, ограничивает эффективность применения аналитического инструментария теории качества жизни.

Поведение внутрироссийских мигрантов в подавляющей массе экономически рационально и обусловлено непринятием риска. Учитывая асимметричность и неполноту информации о дальних регионах, большинство из них мигрирует внутри собственного субъекта РФ. Исключение составляют лишь регионы России - явные лидеры и аутсайдеры по качеству жизни, что вполне объяснимо.

Таким образом, доказана эффективность применения теории качества жизни для выявления и анализа причин внутренней миграции в Российской Федерации на мезоуровне. Внутрироссийские мигранты в подавляющей массе принимают рациональные решения, направленные на повышение доходов и качества жизни, что соответствует постулатам неоклассической экономической теории о рациональном поведении индивидов. Анализ динамики объемов и направлений миграционных потоков устанавливает устойчивую тенденцию доминирования миграционных потоков внутри субъектов РФ по сравнению с миграцией между субъектами РФ.

Общие закономерности внутренней миграции в России подтверждают действие наиболее значимых законов миграции, установленных Э.Г. Равенштейном еще в конце XIX века. Это свидетельствует об общей логике развития миграционных процессов, присущих экономикам развивающегося рынка и позволяет строить более точные прогнозы последствий внутренней миграции в России на основе изучения зарубежного опыта.

\section{Библиографический список}

1. Стратегия социально-экономического развития Республики Татарстан до 2030 года. C. 254. - URL: http:// tatarstan2030.ru/, свободный

2. Chiswick B.R. The Effect of Americanization on the Earnings of Foreign-born Men // The Journal of Political Economy. 1978. Vol. 86. Is.5.pp. 897-921

3. Рейтинг российских регионов по качеству жизни - 2015. - URL: www.riarating.ru//, свободный Рейтинг российских регионов по качеству жизни - 2016. - URL: www.riarating.ru//, свободный Рейтинг российских регионов по качеству жизни - 2017. - URL: www.riarating.ru//, свободный Рейтинг российских регионов по качеству жизни - 2018. - URL: www.riarating.ru//, свободный

4. Российский статистический ежегодник. 2019: Стат.сб./Росстат.- М., 2019-708 с. С. 93-94.

5. Численность и миграция населения Российской Федерации в 2015 г. (Статистический бюллетень).- Москва, 2016. Численность и миграция населения Российской Федерации в 2016 г. (Статистический бюллетень).- Москва, 2017. Численность и миграция населения Российской Федерации в 2017 г. (Статистический бюллетень).- Москва, 2018. Численность и миграция населения Российской Федерации в 2018 г. (Статистический бюллетень).- Москва, 2019.- URL: http://old.gks.ru/wps/wcm/connect/rosstat_main/rosstat/ru/ statistics/publications/catalog/doc_1140096034906 